\title{
Daniel Letendre, Pratiques du présent. Le récit français contemporain et la construction narrative du temps
}

\section{Paola Perazzolo}

\section{(2) OpenEdition}

1 Journals

\section{Edizione digitale}

URL: https://journals.openedition.org/studifrancesi/21742

DOI: $10.4000 /$ studifrancesi.21742

ISSN: 2421-5856

\section{Editore}

Rosenberg \& Sellier

\section{Edizione cartacea}

Data di pubblicazione: 1 décembre 2019

Paginazione: 609-610

ISSN: 0039-2944

\section{Notizia bibliografica digitale}

Paola Perazzolo, «Daniel Letendre, Pratiques du présent. Le récit français contemporain et la construction narrative du temps», Studi Francesi [Online], 189 (LXIII | III) | 2019, online dal 01 mars 2020, consultato il 12 novembre 2021. URL: http://journals.openedition.org/studifrancesi/21742 ; DOI: https://doi.org/ $10.4000 /$ studifrancesi.21742

Questo documento è stato generato automaticamente il 12 novembre 2021.

\section{(c) $(1) \odot$}

Studi Francesi è distribuita con Licenza Creative Commons Attribuzione - Non commerciale - Non opere derivate 4.0 Internazionale. 


\title{
Daniel Letendre, Pratiques du présent. Le récit français contemporain et la construction narrative du temps
}

\author{
Paola Perazzolo
}

\section{NOTIZIA}

Daniel Letendre, Pratiques du présent. Le récit français contemporain et la construction narrative du temps, Montréal, Presses de l'Université de Montréal, 2018, 278 pp.

1 Tratto da una tesi di dottorato, il presente volume analizza la risposta di numerosi autori della letteratura francese contemporanea relativamente alla domanda capitale «qu'est-ce qu'habiter le présent? Qu'est-ce qu'être au présent? Comment faire une expérience durable de ce temps par définition évanescent?» (p.11). Prendendo in considerazione una trentina di testi pubblicati negli ultimi quarant'anni da romanzieri quali Bergounioux, Cadiot, Delaume, Échenoz, Ernaux, Houellebecq e Volodine dal punto di vista dell'enunciazione e della pratica dell'intertestualità o del rapporto che intrattengono con la narrazione e la storia della letteratura, l'A. esamina non solo la loro rappresentazione del tempo presente, ma anche le strategie narrative messe in atto per costruire e restituire un rapporto alla contemporaneità sfuggente ed eternamente rinnovato, per iscrivere il tempo presente nella durata e nella storia, rendendo quindi la narrazione stessa una «pratique du présent» (Quarta di copertina) che partecipa alla costruzione dello stesso. Letendre si interroga infatti sulla restituzione e costruzione del tempo presente quali esse appaiono nelle opere considerate partendo da due questioni fondamentali, una «représentationnelle»«comment l'expérience du présent est-elle rendue, représentée dans le récit contemporain?» - e l'altra «pragmatique» - «comment le présent est-il constitué par le récit contemporain? Quels matériaux mémoriels, narratifs et énonciatifs [...] sont employés pour ce faire, et de quelle manière sont-ils agencés pour le produire?» (p. 253). Al di là di ogni possibile interpretazione ideologica, le opere prese in esame 
risulterebbero quindi, più che contemporanee, "attuali". Nel senso che consentono, grazie a varie strategie narrative «rappelant la narrativité théâtrale, la récitation, le "cut-up"» (p. 262), di andare ben aldilà di una semplice pretesa di rappresentazione e di mettere l'accento sul tempo presente facendo emergere una preoccupazione etica o producendo un effetto politico tramite la creazione di una situazione di dissenso o di conflitto con l'ordine stabilito. Costruendo il presente come un tempo intermedio, non ancora appartenente alla storia, questa stessa temporalità appare quindi come un'alterità instabile, ancora in divenire e potenzialmente estranea agli occhi di un lettore tenuto ad affrontarla secondo modalità che possono essere non consensuali, ma di dissenso.

2 Pur se a tratti redatto in modo un po' involuto, questo lavoro propone un'interessante riflessione su numerosi autori contemporanei, oltre che su modalità e strategie narrative caratterizzate dalla giustapposizione di materiali - storici, memoriali e letterari - eterogenei e da una «instabilité narrative et formelle» (p. 263) che si accorda perfettamente alla percezione di un presente sfuggente e ambiguo che gli autori si preoccupano non solo di rappresentare, ma anche di influenzare. 